\title{
Oxygen Transfer from an Intramolecularly Coordinated Di- aryltellurium Oxide to Acetonitrile. Formation and Combined AIM and ELI-D Analysis of a Novel Diaryltellurium Acetimidate
}

\author{
Ole Mallow, ${ }^{\mathrm{a}}$ Jens Bolsinger, ${ }^{\mathrm{b}}$ Pamela Finke, ${ }^{\mathrm{a}}$ Malte Hesse, ${ }^{\mathrm{a}, \mathrm{b}}$ Yu-Sheng Chen, ${ }^{\mathrm{c}}$ Andrew Duthie, ${ }^{\mathrm{d}}$ \\ Simon Grabowsky, ${ }^{\text {,ee }}$ Peter Luger, ${ }^{b}$ Stefan Mebs, ${ }^{b^{*}}$ and Jens Beckmann ${ }^{a, b^{*}}$ \\ ${ }^{a}$ Institut für Anorganische Chemie, Universität Bremen, Leobener Str. 28359 Bremen, Germany, ${ }^{\mathrm{b}}$ Institut für Chemie und \\ Biochemie, Freie Universität Berlin, Fabeckstr. 34/36, 14195 Berlin, Germany, ${ }^{\mathrm{c}}$ ChemMatCARS, Center for Advanced Radiation \\ Sources, The University of Chicago, 9700 S. Cass Avenue, Argonne, Illinois 60439, USA, ${ }^{\mathrm{d}}$ School of Life and Environmental Sci- \\ ences, Deakin University, Pigdons Road, Waurn Ponds 3217, Australia, ${ }^{\text {e }}$ School of Chemistry and Biochemistry, The University of \\ Western Australia, 35 Stirling Highway, Crawley WA 6009, Australia
}

\begin{abstract}
The reaction of the intramolecularly coordinated diaryltellurium(IV) oxide $\left(8-\mathrm{Me}_{2} \mathrm{NC}_{10} \mathrm{H}_{6}\right)_{2} \mathrm{TeO}$ with acetonitrile proceeds with oxygen transfer and gives rise to the formation of the novel zwitterionic diaryltelluronium(IV) acetimidate $\left(8-\mathrm{Me}_{2} \mathrm{NC}_{10} \mathrm{H}_{6}\right)_{2-}$ $\mathrm{TeNC}(\mathrm{O}) \mathrm{CH}_{3}(1)$ in $57 \%$ yield. Hydrolysis of 1 with hydrochloric acid affords acetamide and the previously known diarylhydroxytelluronium(IV) chloride [(8$\left.\left.\mathrm{Me}_{2} \mathrm{NC}_{10} \mathrm{H}_{6}\right)_{2} \mathrm{Te}(\mathrm{OH})\right] \mathrm{Cl}$.
\end{abstract}

Diaryltellurium oxides, $\mathrm{R}_{2} \mathrm{TeO}$ (e. g. $\mathrm{R}=\mathrm{Ph}, 4^{-\mathrm{MeOC}_{6} \mathrm{H}_{4}, 4^{-}}$ $\mathrm{Me}_{2} \mathrm{NC}_{6} \mathrm{H}_{4}$, Mes), have been utilized as mild oxidizing agents of alcohols, ${ }^{1}$ thiocarbonyls, ${ }^{2}$ arylhydrazines, ${ }^{2,3}$ and transition metal carbonyls. ${ }^{4}$ They catalyze the aldol condensation ${ }^{5}$ and the aerobic oxidation of phosphate esters ${ }^{6}$ and silanes ${ }^{7}$ as well as various reactions involving hydrogen peroxide. ${ }^{8}$ In a preceding paper, we have described the synthesis of the intramolecularly coordinated diaryltellurium oxide (8$\left.\mathrm{Me}_{2} \mathrm{NC}_{10} \mathrm{H}_{6}\right)_{2} \mathrm{TeO}$ and its protolysis with triflic acid giving rise to the formation of the persistent diarylhydroxytelluronium triflate $\left[\left(8-\mathrm{Me}_{2} \mathrm{NC}_{10} \mathrm{H}_{6}\right)_{2} \mathrm{Te}(\mathrm{OH})\right]\left(\mathrm{O}_{3} \mathrm{SCF}_{3}\right) .{ }^{9}$ Attempts to recrystallize $\left(8-\mathrm{Me}_{2} \mathrm{NC}_{10} \mathrm{H}_{6}\right)_{2} \mathrm{TeO}$ from acetonitrile provided a product the microanalysis of which suggested that a simple solvate $\left(8-\mathrm{Me}_{2} \mathrm{NC}_{10} \mathrm{H}_{6}\right)_{2} \mathrm{TeO} \cdot \mathrm{NCCH}_{3}$ had formed. However, during the $\mathrm{X}$-ray crystallographical analysis the product surprisingly turned out to be the novel diaryltellurium acetimidate $\left(8-\mathrm{Me}_{2} \mathrm{NC}_{10} \mathrm{H}_{6}\right)_{2} \mathrm{TeNC}(\mathrm{O}) \mathrm{CH}_{3}$ (1) that was isolated as brown crystals in $57 \%$ yield (Scheme 1) leaving more (slightly impure) product dissolved in the mother liquor. Neither side products nor the related telluride (8$\left.\mathrm{Me}_{2} \mathrm{NC}_{10} \mathrm{H}_{6}\right)_{2}$ Te were found in the reaction mixture. ${ }^{9}$ A literature search brought forward only one other compound containing an acetimidate moiety, namely bis(trimethylstannyl)acetimidate $\left(\mathrm{Me}_{3} \mathrm{Sn}\right)_{2} \mathrm{NC}(\mathrm{O}) \mathrm{CH}_{3}$, which was prepared by the twofold lithiation of acetamide using $n$-butyllithium prior to reaction with two equivalents of trimethyltin chloride. ${ }^{10}$

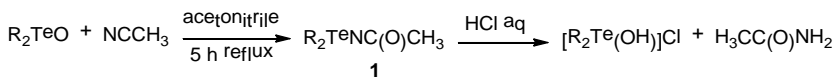

Scheme 1. Formation and acid hydrolysis of (8$\left.\mathrm{Me}_{2} \mathrm{NC}_{10} \mathrm{H}_{6}\right)_{2} \mathrm{TeNC}(\mathrm{O}) \mathrm{CH}_{3}(1)$.

It is also worth mentioning that the free acetimidate dianion is still unknown despite being isoelectronic with acetate. While air stable in the solid state, a solution of (8$\left.\mathrm{Me}_{2} \mathrm{NC}_{10} \mathrm{H}_{6}\right)_{2} \mathrm{TeNC}(\mathrm{O}) \mathrm{CH}_{3}$ (1) in $\mathrm{CH}_{2} \mathrm{Cl}_{2}$ was readily hydrolyzed by $1 \mathrm{M} \mathrm{HCl}$ into acetamide and the previously known diarylhydroxytelluronium chloride $\quad\left[\left(8-\mathrm{Me}_{2} \mathrm{NC}_{10} \mathrm{H}_{6}\right)_{2-}\right.$ $\mathrm{Te}(\mathrm{OH})] \mathrm{Cl}$ (Scheme 1), " which separated well into the aqueous layer and the organic layer, respectively. The unambiguous and quantitative identification of both hydrolysis products was achieved by NMR spectroscopy using authentic substances for comparison. Although the hydrolysis of acetonitrile to acetamide catalyzed by platinum and rhodium complexes is well documented, ${ }^{12}$ the facile activation of the nitrile triple bond by a simple chalcogen oxide is to the best of our knowledge unprecedented and represents another example for main group elements resembling the reactivity of transition metals. ${ }^{13}$ Preliminary experiments revealed that the same diaryltellurium oxide $\left(8-\mathrm{Me}_{2} \mathrm{NC}_{10} \mathrm{H}_{6}\right)_{2} \mathrm{TeO}$ also reacts with propionitrile and benzonitrile giving analogous products, the hydrolysis of which gave propioamide and benzamide. However, no reaction was observed between nitriles and other diaryltellurium oxides, $\mathrm{R}_{2} \mathrm{TeO}\left(\mathrm{R}=\mathrm{Ph}, 4^{-}\right.$ $\mathrm{MeOC}_{6} \mathrm{H}_{4}, 4-\mathrm{Me}_{2} \mathrm{NC}_{6} \mathrm{H}_{4}$, Mes) lacking intramolecularly coordinating $\mathrm{N}$ donor substituents.

Single crystals of $\mathbf{1}$ were always obtained as very fine needles, the dimensions of which were too small for conventional X-ray sources. Thus, the crystallographic data set was obtained using intense synchrotron X-radiation from beamline 15-ID-B of the Advanced Photo Source, USA. 
The quality of the data set was sufficient to distinguish between $\left(8-\mathrm{Me}_{2} \mathrm{NC}_{10} \mathrm{H}_{6}\right)_{2} \mathrm{TeNC}(\mathrm{O}) \mathrm{CH}_{3}$ (1) and the possible alternative $\left(8-\mathrm{Me}_{2} \mathrm{NC}_{10} \mathrm{H}_{6}\right)_{2} \mathrm{TeOC}(\mathrm{N}) \mathrm{CH}_{3}\left(\mathbf{1}^{\prime}\right)$ and to exclude any transposition error between the $\mathrm{N}$ and $\mathrm{O}$ atoms of the acetimidate moiety during the refinement. Switching between both elements lead to an increase of the crystallographic figures of merit from $R_{1}=4.17$ and $w R_{2}=11.05$ for 1 to $R_{1}=4.39$ and $w R_{2}=14.86$ for $\mathbf{1}^{\prime}$ and the atomic displacement parameters for $\mathrm{O}$ and $\mathrm{N}$ of the acetimidate moiety became less physically meaningful. The molecular structure of $\mathbf{1}$ is shown in Figure 1a and selected bond parameters are collected in the caption of the Figure.
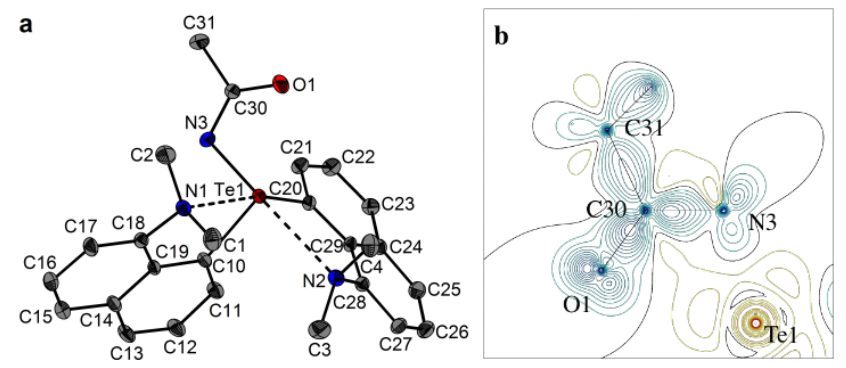

Figure 1.

(a) Molecular structure of 1 showing 90\% probability ellipsoids and the crystallographic numbering

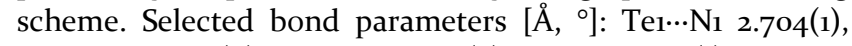
Te1…N2 2.7675(9), Te1-N3 2.oo62(7), Te1-C1o 2.133(1), Te1-C2O 2.1522(9), N3-Te1-C10 9o.65(4), N3-Te1-C20 96.63(3), C10-Te1C2o 94.43(4), N1-Te1-C2O 166.16(3), N2-Te1-N3 166.45(3). Non-bonding distance Te1... $\mathrm{O}_{1} 2.7847$ (9). ORTEP representation. ${ }^{14}$ (b) Experimental deformation density of the acetimidate moiety in 1. XDGRAPH representation. ${ }^{15}$

The spatial arrangement of the Te atom is distorted octahedral when taking into account the stereochemically active lone pair. The coordination sphere of the Te atom is defined by a $\mathrm{C}_{2} \mathrm{~N}+\mathrm{N}_{2}$ donor set. Bond parameters involving Teı and the atoms $\mathrm{N}_{1}, \mathrm{C}_{10}$ and $\mathrm{C}_{2} \mathrm{O}$ of the first coordination sphere fall in the expected range. The Te1 $\cdots \mathrm{N}_{1}$ and $\mathrm{Te}_{1} \cdots \mathrm{N}_{2}$ bond lengths (2.704(1) and 2.7675(9) $\AA$ ) associated with the intramolecular $\mathrm{N}$ donor coordination are in average slightly longer than those of the diarylhydroxytelluronium triflate [ $(8-$ $\left.\left.\mathrm{Me}_{2} \mathrm{NC}_{10} \mathrm{H}_{6}\right)_{2} \mathrm{Te}(\mathrm{OH})\right]\left(\mathrm{O}_{3} \mathrm{SCF}_{3}\right) \quad\left(2.591(5)\right.$ and 2.706(6) $\AA$ ). ${ }^{9}$ Although the Tel...Or distance (2.7847(9) $\AA$ ) is significantly shorter than the sum of the van der Waals radii (ca. 3.5 $\AA$ ) and only marginally longer than the Te $\cdots \mathrm{N}$ bond lengths, it is not related with a bonding interaction due to repulsion of the Te and $\mathrm{O}$ lone pairs (see AIM and ELI-D calculations below). It has been noted previously that the sum of the van der Waals radii is not a sufficient criterion for bonding. ${ }^{19}$ The exceptional quality of the X-ray data set $\left(20 \mathrm{~K}, \sin \theta_{\max } / \lambda=\right.$ 1.05 $\AA^{-1}$ ) prompted a subsequent multipole refinement, which gave a qualitative insight into the charge distribution of $\mathbf{1}$. Despite high residual densities around the Te atom the obtained static deformation densities are of good quality and revealed that the lone pairs of the $\mathrm{O}$ and $\mathrm{N}$ atom of the acetimidate pointing towards the central Te atom are less populated than those on the opposite side (see Figure $1 \mathrm{~b}$ ). Moreover, the lone pair lobes of the $\mathrm{O}$ atom are higher populated than those of the $\mathrm{N}$ atom, which was also confirmed theoretically (see ELI-D calculations below). The ${ }^{125}$ Te MAS NMR spectrum of 1 shows a signal at $\delta_{\text {iso }}=1026.9$. The ${ }^{125} \mathrm{Te}$ NMR spectrum $\left(\mathrm{CDCl}_{3}\right)$ exhibits a reasonably close signal at $\delta$ $=1048.6$, which suggests that the solid-state structure is retained in solution. The ${ }^{13} \mathrm{C}$ NMR spectrum $\left(\mathrm{CDCl}_{3}\right)$ shows 20 signals in the aromatic range and 4 signals in the aliphatic range for the two magnetically inequivalent naphthyl moieties, which is consistent with the spatial arrangement found in the solid-state. In addition, the ${ }^{13} \mathrm{C}$ NMR spectrum $\left(\mathrm{CDCl}_{3}\right)$ reveals two signals at $\delta=103.2$ and 22.1 for the acetimidate moiety, which are shifted lowfield and highfield, respectively, compared to those of acetonitrile (116.4 and 1.9). The ${ }^{1} \mathrm{H}$ NMR spectrum $\left(\mathrm{CDCl}_{3}\right)$ shows a signal at $\delta=1.82$ for the acetimidate moiety, which is lowfield shifted with respect to related signal of acetonitrile (2.10).

In an effort to shed light on the relative stability of (8$\left.\mathrm{Me}_{2} \mathrm{NC}_{10} \mathrm{H}_{6}\right)_{2} \mathrm{TeNC}(\mathrm{O}) \mathrm{CH}_{3}(\mathbf{1})$ and the possible alternative (8$\left.\mathrm{Me}_{2} \mathrm{NC}_{10} \mathrm{H}_{6}\right)_{2} \mathrm{TeOC}(\mathrm{N}) \mathrm{CH}_{3}\left(\mathbf{1}^{\prime}\right)$, DFT calculations were carried out in the gas phase and compared with the starting compounds $\left(8-\mathrm{Me}_{2} \mathrm{NC}_{10} \mathrm{H}_{6}\right)_{2} \mathrm{TeO}$ and acetonitrile as well as with the hypothetical products of an electrolytic dissociation process, namely the diaryltellurium dication (8$\left.\mathrm{Me}_{2} \mathrm{NC}_{10} \mathrm{H}_{6}\right)_{2} \mathrm{Te}^{2+}$ and the elusive acetimidate dianion. The geometry optimization of 1 gave a minimum structure, the geometrical parameters of which compare well with the experimental molecular structure. Attempts to optimize $\mathbf{1}^{\prime}$ starting from various meaningful geometries gave always rise to the transposition of $\mathrm{O}$ and $\mathrm{N}$ and resulted in the same minimum structure of $\mathbf{1}$. However, it turned out that $\mathbf{1}^{\prime}$ is a first order transition state (one imaginary frequency) on the reaction pathway going from $\left(8-\mathrm{Me}_{2} \mathrm{NC}_{10} \mathrm{H}_{6}\right)_{2} \mathrm{TeO}$ and acetonitrile to 1 . Thus, a likely reaction mechanism accounting for 1 might involve the formation an initial complex between $\left(8-\mathrm{Me}_{2} \mathrm{NC}_{10} \mathrm{H}_{6}\right)_{2} \mathrm{TeO}$ and acetonitrile, which then converts via the transition state $\mathbf{l}$ ' comprising a four-membered ring Te$\mathrm{O}-\mathrm{C}=\mathrm{N}$ into the stable product $\mathbf{1}$. The optimized structures and the relative energies are shown in Figure 2.

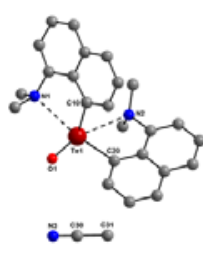

$0 \mathrm{KJ} / \mathrm{mol}$

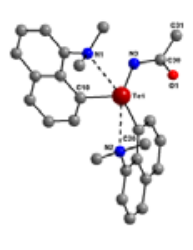

$-80 \mathrm{KJ} / \mathrm{mol}$

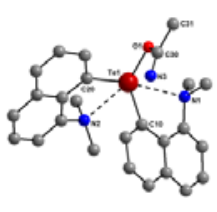

$178 \mathrm{KJ} / \mathrm{mol}$

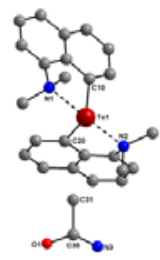

$1846 \mathrm{KJ} / \mathrm{mol}$
Figure 2.

Geometry and relative energies of (8$\left.\mathrm{Me}_{2} \mathrm{NC}_{10} \mathrm{H}_{6}\right)_{2} \mathrm{TeO}$ and $\mathrm{NCCH}_{3}, \quad \mathbf{1}, \quad \mathbf{1}^{\prime}$ as well as (8$\left.\mathrm{Me}_{2} \mathrm{NC}_{10} \mathrm{H}_{6}\right)_{2} \mathrm{Te}^{2+}$ and $\mathrm{N}(\mathrm{O}) \mathrm{CCH}_{3}^{2-}$.

The energy of the starting materials was arbitrarily set to o $\mathrm{KJ} \mathrm{mol}^{-1}$. Compared to this reference, the energy of $\mathbf{1}$ is lower $(-8 \mathrm{o} \mathrm{KJ} / \mathrm{mol})$, whereas that of $\mathbf{1}^{\prime}$ is higher $(178 \mathrm{KJ} / \mathrm{mol})$. Thus, $\mathbf{1}$ is by $258 \mathrm{KJ} / \mathrm{mol}$ more stable than $\mathbf{1}$, which is consistent with result of the X-ray refinement. As expected for isolated ions in the gas phase the energy of the diaryltellurium dication $\left(8-\mathrm{Me}_{2} \mathrm{NC}_{10} \mathrm{H}_{6}\right)_{2} \mathrm{Te}^{2+}$ and the elusive acetimidate dianion is substantially higher $(1846 \mathrm{KJ} / \mathrm{mol})$; high enough to exclude that electrolytic dissociation of $\mathbf{1}$ takes place in any strongly solvating solvents. 
Furthermore, the electronic structure of the calculated compounds was investigated using electron and pair densities derived from the resulting wavefunction files, which were topologically analyzed according to $\mathrm{AIM}^{17}$ and ELI-D ${ }^{16}$ space-partitioning schemes, respectively. These concepts provide reliable atomic and bonding properties and complement wavefunction-based methods, such as molecular orbitals (MO) and natural bond orbitals (NBO). ${ }^{20}$ The topological analysis of the electron density of $\mathbf{1}$ according to the AtomsIn-Molecules (AIM) ${ }^{17}$ theory provided bond critical points (bcp's) between the Te atom and all $\mathrm{N}$ and $\mathrm{C}$ atoms within the direct coordination sphere of the Te atom (Figure $3 \mathrm{a}$ ), however, not between the Te atom and the $\mathrm{O}$ atom of the acetimidate moiety.

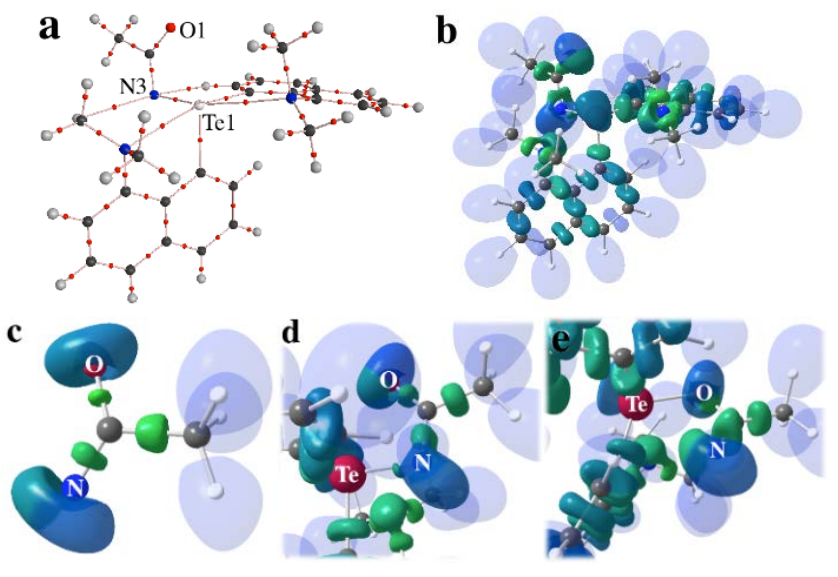

Figure 3.

(a) Bond paths motif for the optimized geometry of $\mathbf{1}$. For clarity, weak $\mathrm{H} \cdots \mathrm{H}$ interactions and ring critical points are omitted. AIM2ooo representation. ${ }^{18}$ (b)-(e) Iso-surface representations of the ELI-D (Y) for $\mathbf{1}$, the acetimidate dianion and details for $\mathbf{1}$ and $\mathbf{1}^{\prime}(\mathrm{Y}=1.4)$. Mollso representation. $^{22}$

Iso-surface representations of the ELI-D for 1, 1' and the acetimidate dianion are displayed in Figure $3 b-3 e$. Results for the remaining structures are given in the ESI. In the free acetimidat dianion, both the $\mathrm{O}_{1}$ and the $\mathrm{N}_{3}$ atom exhibit two non-bonding lone pairs, one pointing to the opposite $\mathrm{N}_{3} / \mathrm{O}_{1}$ atom ("inner" lone pair), one pointing towards the methyl group $\mathrm{H}$ atoms ("outer" lone pair). Due to the sterical demands the "inner" lone pair basins (which interfere with each other) are considerably smaller and less populated than those which point towards the $\mathrm{H}$ atoms of the methyl group. This asymmetry is drastically enhanced for $\mathbf{1}$ and $\mathbf{1}$ (Figures $3 \mathrm{~b} / \mathrm{c}$ ) and much more pronounced for the $\mathrm{N}_{3}$ atom than for the $\mathrm{O}_{1}$ atom which is due to the fact that $\mathrm{N}$ is easier to be polarized than $\mathrm{O}$. The reason for the above mentioned missing Te-O 1 bcp in $\mathbf{1}$ is the sterical hindrance and electronic repulsion between the "inner" $\mathrm{O}_{1}$ atom lone pair of the acetimidate and the nonbonding electron pair of the Te atom (Figure 3b). Quantitative results for the AIM charges, the ELI-D populations and the corresponding Raub-JansenIndices (RJI), ${ }^{23}$ which are derived by overlapping ELI-D bonding basins with AIM atomic basins and subsequent integration of the electron populations were calculated. For homopolar bonds, the RJI is $50 \%$ and increases with increasing bond polarity to the extreme of $95 \%$ and larger for dative ${ }^{24}$ and ionic bonds and to $100 \%$ for almost non-bonding or weak Coloumb interactions. The AIM charges of the 8dimethylaminonaphthyl substituents of all compounds under consideration are almost unaffected by the different chemical environments of the Te1 atom. The most obvious effect of the third substituent (O1 atom and acetimidate, respectively) is the significant elongation/weakening of the Te1- $\mathrm{N}_{1}$ and $\mathrm{Te} 1-\mathrm{N}_{2}$ bonds in $\left(8-\mathrm{Me}_{2} \mathrm{NC}_{10} \mathrm{H}_{6}\right)_{2} \mathrm{TeO}, \mathbf{1}$ and $\mathbf{1}^{\prime}$, which lead to almost non-bonding Te1-N1 and Te1-N2 interactions as reflected in RJI-values of $100 \%$. Interestingly, the electron population of the Te1 atoms lone pair is quite unaffected so mainly the Te1- $\mathrm{N}_{1}$, Te1-N2, Te1-C1o and Te1-C2o bonds seem to modulate the electronic requirements of the Te1 atom.

By contrast, pronounced and oppositely directed electron redistributions occur within the $\mathrm{O}_{1}-\mathrm{C}_{3} \mathrm{O}-\mathrm{N}_{3}$ fragment of the acetimidate ligand in $\mathbf{1}$ and $\mathbf{1}$ '. In $\mathbf{1}$, the electron populations of the $\mathrm{N}_{3}$ atom lone pairs and of the $\mathrm{O}_{1}-\mathrm{C}_{30}$ bond are significantly enhanced, whereas those of the $\mathrm{O}_{1}$ atom lone pairs and of the $\mathrm{N}_{3}-\mathrm{C}_{3}$ o bond are significantly reduced. For 1', the opposite effect is observed (Figure ze). The RJI proves the Te$\mathrm{O} 1$ interactions in $\left(8-\mathrm{Me}_{2} \mathrm{NC}_{10} \mathrm{H}_{6}\right)_{2} \mathrm{TeO}$ and $\mathbf{1}^{\prime}$ to be mainly ionic, whereas a polar covalent Te- $\mathrm{N}_{3}$ interaction is formed in 1. In both compounds formally an electron donor $(\mathrm{N}$ or $\mathrm{O}$ atom) donates charge to an electron acceptor (Te atom), which, however, can deal only with a limited amount of charge. Due to this, the $\mathrm{N}$ atoms of the 8dimethylaminonaphthyl substituents become electronically oversaturated once a third substituent appears and retreat from the coordination to the Te atom. Additionally, the hypothetical formation of $\mathbf{1}$ and $\mathbf{1}$ ' from the diaryltellurium dication $\left(8-\mathrm{Me}_{2} \mathrm{NC}_{10} \mathrm{H}_{6}\right)_{2} \mathrm{Te}^{2+}$ and the elusive acetimidate dianion leads to an electronic back loop effect into the third substituent which is handled differently by the $\mathrm{N}_{3}$ and $\mathrm{O}_{1}$ atoms. Te- $\mathrm{N}_{3}$ bonding is preferred, because the unbound lone pair of the more polarizable ("softer") $\mathrm{N}_{3}$ atom can compensate for the electron excess (Figures $3 \mathrm{~b}$ ) so that a mainly covalent $\mathrm{Te}-\mathrm{N}_{3}$ bond is formed, as mentioned above. However, the lone pair electrons of the less polarizable ("harder") $\mathrm{O}_{1}$ atom do not even form a Te-O bonding basin (Figure 3d). The formal Te-O double bond of (8$\left.\mathrm{Me}_{2} \mathrm{NC}_{10} \mathrm{H}_{6}\right)_{2} \mathrm{TeO}$ is special as it has both strongly covalent and strongly ionic contributions. Like for $\mathbf{1}$, the ionicity of $\left(8-\mathrm{Me}_{2} \mathrm{NC}_{10} \mathrm{H}_{6}\right)_{2} \mathrm{TeO}$ is reflected in the fact that no Te-O bonding basin is present). One of the $\mathrm{O}$ atom lone pairs is closer to the Te atom but overlaps only to $8 \%$ with the AIM Te atom, a typical value for ionic and dative bonds. Additionally, the Laplacian of the electron density at the bond critical point is considerably positive. The covalency on the other hand is reflected by large source contributions ${ }^{25}$ of the direct bond partners, $\mathrm{Te}+\mathrm{O}=92.7 \%$ and the quite negative total energy density over $\rho(\mathbf{r})_{\text {bcp }}$ ratio $H / \rho\left(r_{b c p}\right)$ ratio $=-0.58$ $\mathrm{eh}^{-1}$. The partial double bond character leads to strong electron sharing, delocalization index $\delta(\mathrm{Te}, \mathrm{O})=1.29^{26}$ (the cylindrical symmetry of the formal Te-O double bond prevents an elliptical shape of the bonding density, thus $\varepsilon=0.01$ ). This strong interaction leads to a penetration of the $\mathrm{O}$ atoms valence electrons into the outer core region of the Te atom which increases the kinetic density over rho ratio to $G / \rho\left(r_{b c p}\right)$ $=1.33 \mathrm{eh}^{-1}$. 
In comparison, all bond descriptors of the Te-O1 interaction of $\mathbf{1}^{\prime}$ are less pronounced, those which represent ionicity as well as covalency. Moreover, also the O1-C 30 bond in $\mathbf{1}^{\prime}$ is quite weak which is reflected by all AIM and ELI-D bond properties. Due to the complex bonding situation in the central $\mathrm{Te}_{-} \mathrm{N}_{3}-\mathrm{C}_{3} \mathrm{O}-\mathrm{O}_{1}$ region and the high degree of electron delocalization, the interpretation of the AIM charges of these four atoms is ambiguous. For such cases, the benefit of a complementary ELI-D analysis becomes apparent.

\section{ASSOCIATED CONTENT}

\section{Supporting Information}

Synthesis and acid hydrolysis of $\mathbf{1}$. Computational details of $\mathbf{1}$, $\mathbf{I}^{\prime}$ and related species. Crystallographic data in cif format.This information is available free of charge via the Internet at http://pubs.acs.org/.

\section{AUTHOR INFORMATION}

\section{Corresponding Author}

Correspondence to Jens Beckmann: E-mail: j.beckmann@unibremen.de and Stefan Mebs: E-mail: stebs@chemie.fuberlin.de

\section{Notes}

The authors declare no competing financial interests.

\section{ACKNOWLEDGMENT}

This work is dedicated to Prof. Dr. Konrad Seppelt on the occasion of his $70^{\text {th }}$ birthday. P.L. is grateful to the Deutsche Forschungsgemeinschaft (DFG) for financial support within special priority program SPP1178 ("Experimental Electron Density as Key to Understanding Chemical Interactions"). S. G. acknowledges the Australian Research Council (ARC) for funding within the ARC Discovery Early Career Researcher Award DE140101330 and within the ARC Discovery Project DP110105347. ChemMatCARS Sector 15 is principally supported by the National Science Foundation/Department of Energy under Grant Number NSF/CHE-0822838. Use of the Advanced Photon Source was supported by the U.S. Department of Energy, Office of Science, Office of Basic Energy Science, under Contract No. DE-ACo2-o6CH11357.

\section{REFERENCES}

(1) Oba, M.; Endo, M.; Nishiyama, K.; Ouchi, A.; Ando, W. Chem. Commun. 2004, 1672-1673.

(2) Barton, D. H. R.; Ley, S. V.; Meerholz, C. A. J. Chem. Soc. Chem. Commun. 1979, 755-756.

(3) Ley, S. V.; Meerholz, C. A.; Barton, D. H. Tetrahedron Suppl. 1981, 37, $213-223$.

(4) (a) Shen, J. K.; Gao, Y.; Shi, Q.; Rheingold, A. L.; Basolo, F. Inorg. Chem. 1991, 30, 1868-1873. (b) Xue, M.; Gao, Y. C.; Shen, J. K.; Shi, Q. Z.; Basolo, F. Inorg. Chim. Acta 1993, 207, 207-212. (c) Liu, X.; Gao, Y. C.; Su, Z. X.; Wang, Y. Y.; Shi, Q. Z. Trans. Met. Chem. 1999, 24, 666668. (d) Song, L. C.; Li, Q. S.; Hu, Q. M.; Dong, Y. B. J. Organomet. Chem. 2001, 619, 194-203.

(5) (a) Engman, L.; Cava, M. P. Tetrahedron Lett. 1981, 22, 5251-5252. (b) Akiba, M.; Lakshmikantham, M. V.; Jen, K.-Y.; Cava, M. P. J. Org. Chem. 1984, 49, 4819-4821.
(6) Oba, M.; Okada, Y.; Nishiyama, K.; Ando, W. Org. Lett. 2009, 11, 1879-1881.

(7) Okada, Y.; Oba, M.; Arai, A.; Tanaka, K.; Nishiyama, K.; Ando, W. Inorg. Chem. 2010, 49, 383-385.

(8) (a) Detty, M. R.; Gibson, S. L. Organometallics 1992, 11, 2147-2156. (b) Engman, L.; Stern, S.; Pelcman, M.; Andersson, C. M. J. Org. Chem. 1994, 59, 1973-1979. (c) Detty, M. R.; Friedman, A. E.; Oseroff, A. R. J. Org. Chem. 1994, 59, 8245-8250. (d) Vessman, K.; Ekstroem, M.; Berglund, M.; Andersson, C.-M.; Engman, L. J. Org. Chem. 1995, 6o, 4461-4467. (e) Leonard, K. A.; Zhou, F.; Detty, M. R. Organometallics 1996, 15, 4285-4292. (f) Detty, M. R.; Zhou, F.; Friedman, A. E. J. Amer. Chem. Soc. 1996, 118, 313-318. (g) Kanda, T.; Engman, L.; Cotgreave, I. A.; Powis, G. J. Org. Chem. 1999, 64, 8161-8169. (h) Higgs, D. E.; Nelen, M. I.; Detty, M. R. Org. Lett. 20o1, 3, 349-352. (i) Francavilla, C.; Drake, M. D.; Bright, F. V.; Detty, M. R. J. Amer. Chem. Soc. 2001, 123, 57-67. (j) You, Y.; Ahsan, K.; Detty, M. R. J. Amer. Chem. Soc. 2003, 125, 4918-4927. (k) Ahsan, K.; Drake, M. D.; Higgs, D. E.; Wojciechowski, A. L.; Tse, B. N.; Bateman, M. A.; You, Y.; Detty, M. R. Organometallics 2003, 22, 2883-2890.

(9) Beckmann, J.; Bolsinger, J.; Duthie, A.; Finke, P. Organometallics 2012, 31, 238-245.

(10) Geetha, S.; Ye, M.; Verkade, J. G. Inorg. Chem. 1995, 34, 61586162.

(11) Beckmann, J.; Bolsinger, J.; Duthie, A.; Finke, P. Dalton Trans. 2013, 42, 12193-12202.

(12) Kukushkin, V. Y.; Pombeiro, A. J. L. Inorg. Chim. Acta 2005, 358, 1-21.

(13) Power, P. P. Nature 2010, 463, 171-177.

(14) Burnett, M. N.; Johnson, C. K. ORTEP-III, Oak Ridge Thermal Ellipsoid Plotting Program for Crystal Structure Illustrations, Report ORNL-6895, Oak Ridge National Laboratory, Tennessee TN, USA, 1996.

(15) Volkov, A.; Macchi, P.; Farrugia, L. J.; Gatti, C.; Mallinson, P. R.; Richter, T.; Koritsanszky, T. XD2006 - a computer program for multipole refinement, topological analysis and evaluation of intermolecular energies from experimental and theoretical structure factors, University at Buffalo, NY, (USA); University of Milano, (Italy); University of Glasgow, (UK); CNRISTM, Milano, (Italy); Middle Tennessee State University, TN, (USA), 2006.

(16) Wagner, F. R.; Kohout, M.; Grin, Y. J. Phys. Chem. A 2008, 112, 9814-9828.

(17) Bader, R. F. W. Atoms in Molecules, Clarendon Press, Oxford, 1st edn., 1990.

(18) Biegler-König, F.; Schönbohm, J.; Bayles, D. J. Comp. Chem. 2001, 22, 545-559.

(19) Schiemenz, G. P. Z. Naturforsch. 2007, 62b, 235-243.

(20) Foster, J. P.; Weinhold, F. J. Am. Chem. Soc. 1980, 102, 7211-7218.

(21) van Duijneveldt, F. B., van Duijneveldt-van de Rijdt, J. G. C. M:, van Lenthe, J. H. Chem. Rev. 1994, 94, 1873-1885.

(22) Hübschle, C. B., Luger, P. J. Appl. Crystallogr. 2006, 39, 901-904.

(23) Raub, S.; Jansen, G. Theor. Chem. Acc. 20o1, 106, 223-232.

(24) (a) Mebs, S.; Grabowsky, S.; Förster, D.; Kickbusch, R.; Hartl, M.; Daemen, L. L.; Morgenroth, W.; Luger, P.; Paulus, B.; Lentz, D. J. Phys. Chem. A 2010, 114, 10185-10196. (b) Mebs, S.; Kalinowski, R.; Grabowsky, S.; Förster, D.; Kickbusch, R.; Justus, E.; Morgenroth, W.; Paulmann, C.; Luger, P.; Gabel, D.; Lentz, D. J. Phys. Chem. A 2011, 115, 1385-1395.

(25) (a) Bader, R. F. W.; Gatti, C. Chem. Phys. Lett. 1998, 287, 233-238 (b) Gatti, C.; Cargnoni, F.; Bertini, L. J. Comput. Chem. 2003, 24, 422436.

(26) (a) Bader, R. F. W.; Stephens, M. E. J. Am. Chem. Soc. 1975, 97, 7391-7399. (b) Fradera, X.; Austen, M. A.; Bader, R. W. F. J. Phys. Chem. A 1999, 103, 304-314. 
TOC entry:

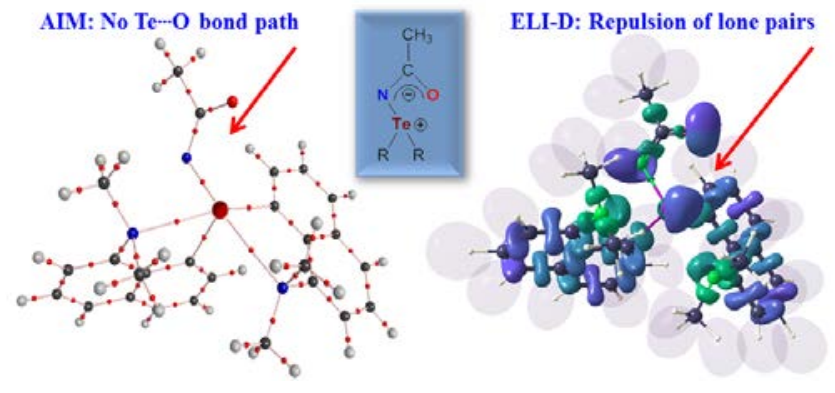

